\title{
In situ analysis of Her 2 DNA and RNA in retinoblastoma and adjacent retina
}

\author{
Gail M Seigel ${ }^{1}$, Dhaval K Shah², Pia Mendoza ${ }^{3}$, Ezster Szalai $^{3}$, Hans Grossniklaus ${ }^{3}$, \\ Yinghui Song ${ }^{4}$, Jidong Shan ${ }^{4}$ \\ ${ }^{1}$ University at Buffalo, Center for Hearing and Deafness, Buffalo, NY \\ ${ }^{2}$ University at Buffalo, Department of Pharmaceutical Sciences, Buffalo, NY \\ ${ }^{3}$ Emory Eye Center, Emory University, Atlanta, GA \\ ${ }^{4}$ Molecular Cytogenetic Core, Albert Einstein College of Medicine, NY \\ Correspondence to: Gail M. Seigel, email: gseigel@buffalo.edu
}

Keywords: Retinoblastoma; Her2; Adjacent tissues

Received: April 04, $2019 \quad$ Accepted: May 15, $2019 \quad$ Published: August 23, 2019

Copyright: Seigel et al. This is an open-access article distributed under the terms of the Creative Commons Attribution License 3.0 (CC BY 3.0), which permits unrestricted use, distribution, and reproduction in any medium, provided the original author and source are credited.

\section{ABSTRACT}

Retinoblastoma (RB) is an ocular tumor of early childhood. Current treatments attempt to preserve visual function, but may spare chemoresistant tumor cells. One potential therapeutic target for RB is HER2, (ERBB2), expressed in RB in truncated form. In this study, we tested the hypothesis that Her2 DNA and RNA are expressed in RB tumors and adjacent retina. We examined 24 human RB tumors as well as normal-appearing adjacent retinal tissues for Her2 DNA and RNA expression by in situ hybridization. We also examined 28 RB tumors for HER2 protein immunoreactivity. 21/22 RB tumors expressed Her2 DNA and 14/19 tumors expressed Her2 RNA. In 17 paired cases, there were three cases in which Her2 DNA was detected, but not RNA. We also saw Her2 RNA signal in six instances of "normal" adjacent retinal tissue. Heterogeneous HER2 protein expression in specific tumor regions also was confirmed by quantitative HER2 immunohistochemistry. In summary, Her2 DNA and RNA are expressed in many RB tumors, and in some adjacent ocular tissues, with hetereogenous protein expression throughout. These results may provide important insights regarding RB tumor progression, and drug targeting approaches designed to spare the eye, preserve vision and improve quality of life for RB patients.

\section{INTRODUCTION}

Human epidermal growth factor receptor 2 (HER2, ERBB) is a cancer biomarker and drug target encoded on human chromosome 17q21-22 [1]. It is expressed in a variety of malignancies [2, $3,4,5]$ and is associated with a poor prognosis [6]. Recently, our group reported on HER2 expression in retinoblastoma, an ocular tumor of childhood [7]. This was an unexpected finding at the time, since a previous study had suggested that HER2 would not be expressed in RB [8]. This negative prediction was based on immunohistochemistry of RB tumors using only one antibody [8]. Our results provided a potential explanation for this inconsistency, as the HER2 expressed in retinoblastoma appeared to be a truncated protein, not detectable by some antibodies directed against the missing portions of the protein [7].

Our 2016 study demonstrated HER2 expression in retinoblastoma tumors (and its absence in normal ocular tissues) by multiple methods, including immunohistochemistry, flow cytometry, RT-PCR and western immunoblot [7], but not in situ hybridization. This study focused on the tumor itself, without analysis of adjacent retinal tissues. A subsequent study by Sousa and colleagues questioned the extent of HER2 expression in retinoblastoma, as the protein was immunonegative in 49/60 retinoblastoma cases 
and very low in $11 / 60$ cases that they tested [9]. Since the Sousa study involved one of the same antibodies used in our study (Sigma, HPA001383), the simplest explanation for this conflicting result was a difference in methodology (shorter incubation periods, different detection methods).

Our present study demonstrates new and important characteristics of Her2 expression in retinoblastoma by analyzing DNA and RNA expression in retinoblastoma tumors, including adjacent retinal tissue, as well as regional Her2 immunoreactivity within the tumor itself. To this end, we examined 24 retinoblastoma tumors and adjacent ocular tissue by fluorescent and colorimetric in situ hybridization, specifically DNA-FISH and RNA-CISH. We followed up with additional HER2 immunohistochemistry of 28 RB tumors in different zones (central tumor, transitional zone, leading edge, vitreous seeds) to assess regional differences in HER2 immunoreactivity. Positive results in RB tumors and adjacent tissues reveal the utility of FISH-DNA and CISH-RNA analysis in assessing Her 2 expression in retinoblastoma for potential drug targeting approaches and studies of tumor progression.

\section{RESULTS}

For FISH and CISH analyses, a total of 24 retinoblastoma cases were examined, with 17 paired cases that were tested for both FISH and CISH. A summary of these results is shown in Table 1, with the unpaired cases shaded. For FISH, a total of 21/22 RB tumors expressed some Her2 DNA, while 14/19 RB tumors expressed some Her2 RNA by CISH. For direct comparison, 17 paired RB cases were tested for both FISH and CISH; in three of these cases Her2 DNA was detected, but not RNA.

\section{Visualization of Her2 DNA-FISH in RB}

DNA-FISH results were visualized by fluorescent microscopy, with representative images shown in Figure 1. Her 2 signals (red) are visible in panels $\mathrm{B}$ and $\mathrm{C}$ that contrast with the negative control probe image in panel (A). Although there was heterogeneity of Her2 DNA expression among the tumors examined, there was clear Her2 DNA expression in 22/23 of tumors tested. The only Her2 negative tumor by DNA-FISH was tumor RB10, staged as T2aN0MX, with minimal tumor spread.
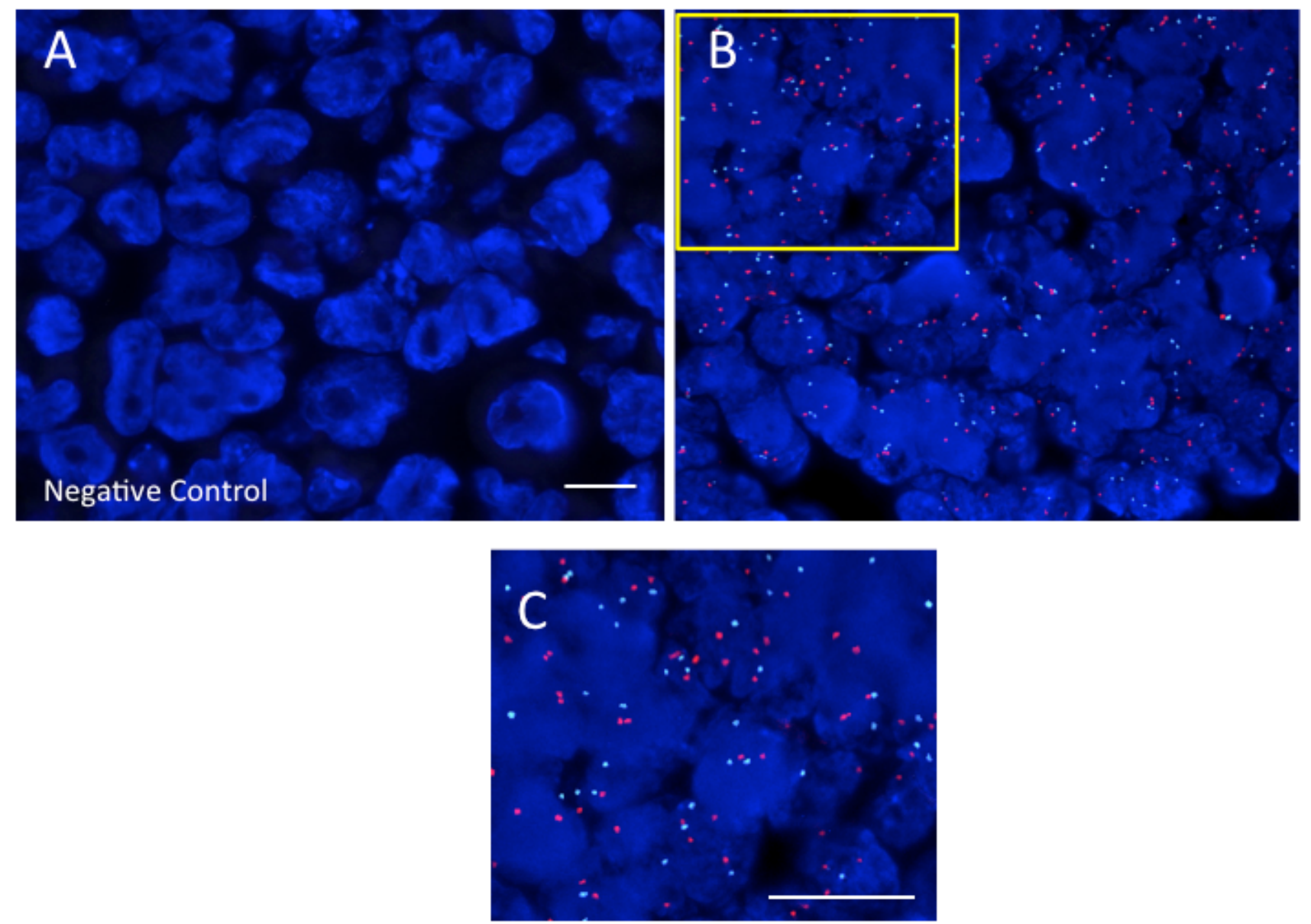

Figure 1: Her2 DNA expressed in RB tumors. Fluorescence in situ hybridization (FISH) images of Her2 DNA signal (red) in paraffin embedded retinoblastoma tumor samples. Panel A: Negative control probe; Panel B: Retinoblastoma tumor with red Her2 signal, with the yellow square shown as a higher magnification inset [Panel C]. Scale bars $=5$ microns. 
Table 1: Her2 FISH and CISH in retinoblastoma tumors and control tissues. Her2 FISH and CISH were performed according to Methods, with individual results for each tumor sample, alongside clinical information when available. Shaded rows indicate tumors that were not paired for both FISH and CISH.

\begin{tabular}{|c|c|c|c|}
\hline Sample & Staging & Her2 FISH DNA & Her2 CISH RNA \\
\hline Array A 1,2 RB & T3cN0M0 & low & low \\
\hline Array A 3,4 RB & T4bN0M0 & + & - \\
\hline Array A 5,6 RB & T2N0M0 & + & + \\
\hline Array A 7,8 RB & T2N0M0 & + & + \\
\hline Array B 1,2 RB & T3cN0M0 & + & + \\
\hline Array B 3,4 RB & T2N0M0 & + & + \\
\hline Array B 5,6 RB & T3aN0M0 & + & + \\
\hline Array B 7,8 RB & T2N1M0 & + & + \\
\hline Array C 1,2 RB & T3N0M0 & + & + \\
\hline Array C 3,4 RB & T2N0M0 & + & + \\
\hline Array C 5,6 RB & T2N0M0 & + & - \\
\hline Array C 7,8 RB & T3bN0M0 & + & + \\
\hline Array D 1,2 RB & T3aN0M0 & low & low \\
\hline Array D 3,4 RB & TINOM0 & + & - \\
\hline RB2 & T3bpNXcM0 & + & N/A \\
\hline RB4 & T3bNXMX & N/A & - \\
\hline RB5 & T2bpNXpMX & + & $\mathrm{N} / \mathrm{A}$ \\
\hline RB6 & T3bNXMX & + & N/A \\
\hline RB10 & T2aN0MX & - & - \\
\hline RB11 & T3bNXM & N/A & + \\
\hline RB17 & T1NXMX & + & N/A \\
\hline RB18 & T3bNXMX & + & $\mathrm{N} / \mathrm{A}$ \\
\hline RB19 & T1NXMX & + & + \\
\hline RB20 & T3bNXMX & + & + \\
\hline
\end{tabular}




\begin{tabular}{|l|l|l|l|}
\hline Sample & Staging & Her2 FISH DNA & Her2 CISH RNA \\
\hline Her+ xenograft (pos control) & N/A & + & + \\
\hline Adrenal tumor (neg control) & N/A & - & - \\
\hline
\end{tabular}

\section{Visualization of Her2 RNA-CISH in RB}

RNA-CISH results were visualized by brightfield microscopy, with examples shown in Figure 2. A Her2 negative adrenal gland tumor (panel A) and a positive control Her2+ xenograft (panel B) are seen in comparison with Her2-expressing RB tumors (low-moderate, Panel $\mathrm{C}$; high, Panel D). Her2 RNA expression was detected in 14/19 RB tumors tested, with some heterogeneity within the tissues. In 17 paired cases of RB tested for both DNAFISH and RNA-CISH, there were three cases in which we did not detect Her2 RNA, although these samples did express Her2 DNA as shown in Table 1.

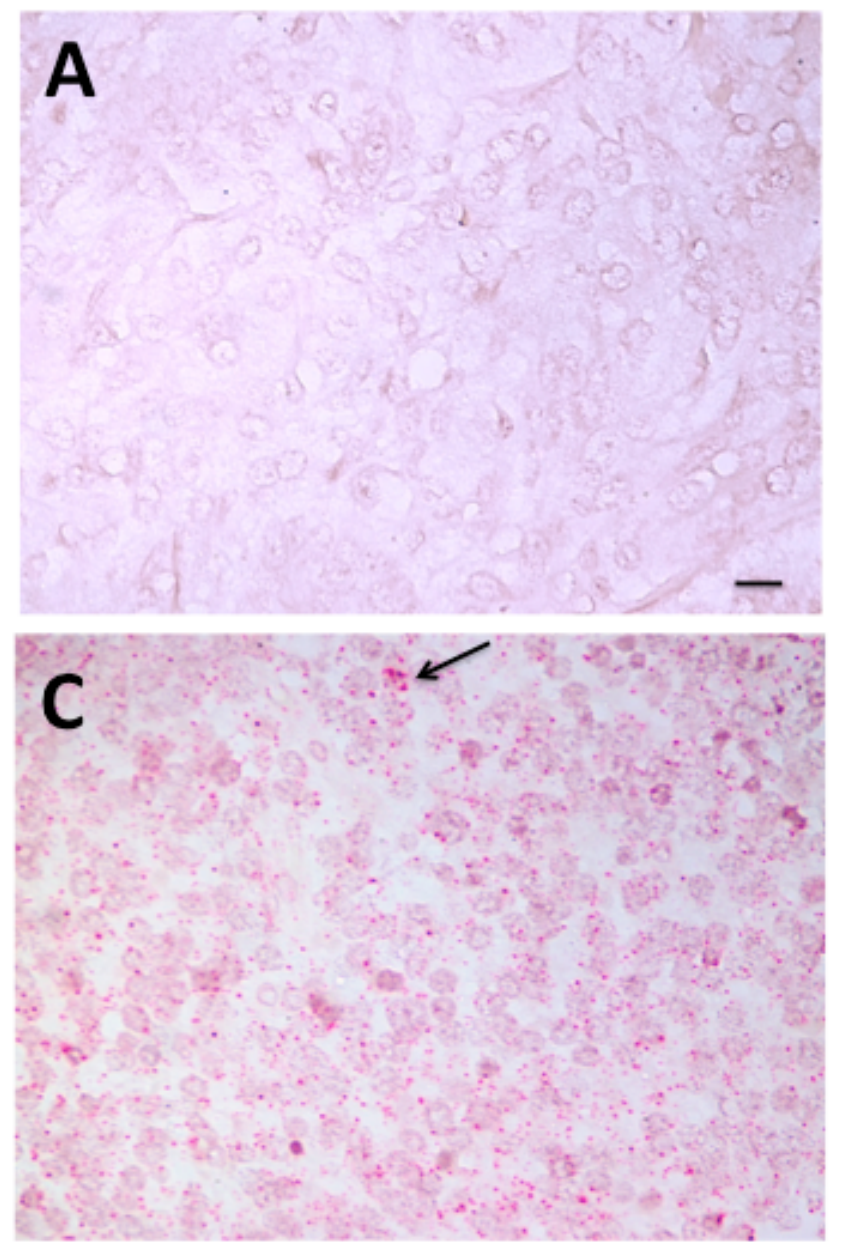

Her2 expression in adjacent retina and optic nerve

Histologically normal tissue adjacent to a tumor is often used as control tissue in comparative tumor studies. However, little is known about the characteristics of this adjacent tissue, how it is influenced by the tumor, and how it compares with non-tumor-bearing tissues. We took this opportunity to examine normal adjacent retinal tissue in these RB cases to determine whether we could detect Her2. In six separate RB cases, we observed Her2 DNA and/or RNA expression in the adjacent retina, one example

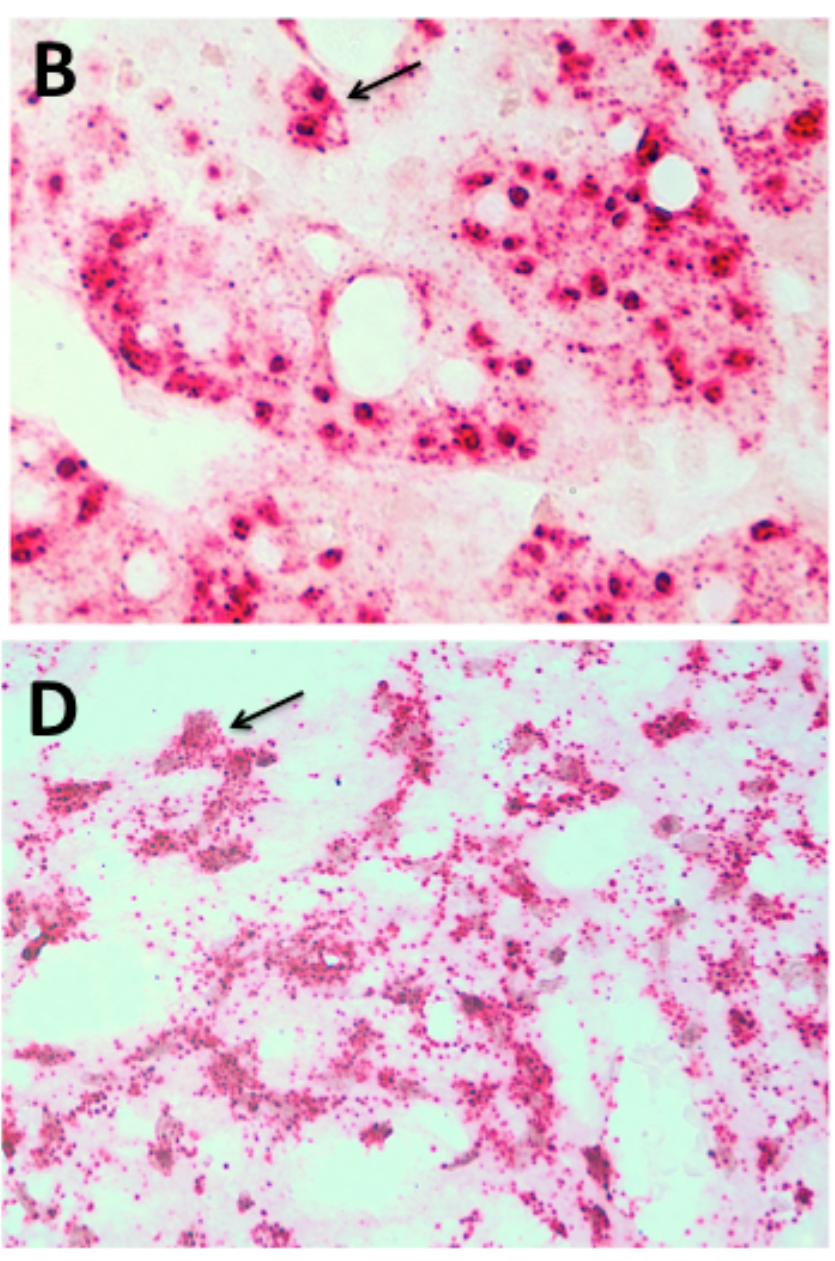

Figure 2: Her2 RNA expressed in RB tumors. Colorimetric in situ hybridization (RNA-CISH) images of Her2 RNA signal (red puncta) in paraffin embedded tissue samples. Panel A: Negative control tissue (pheochromocytoma tumor); Panel B: Her+ xenograft ; Panel C: Her2 signal in a moderately-expressing retinoblastoma tumor; Panel D: Her2 signal in a high-expressing retinoblastoma tumor. Arrows point to examples of Her2 signal. Scale bar $=5$ microns. 

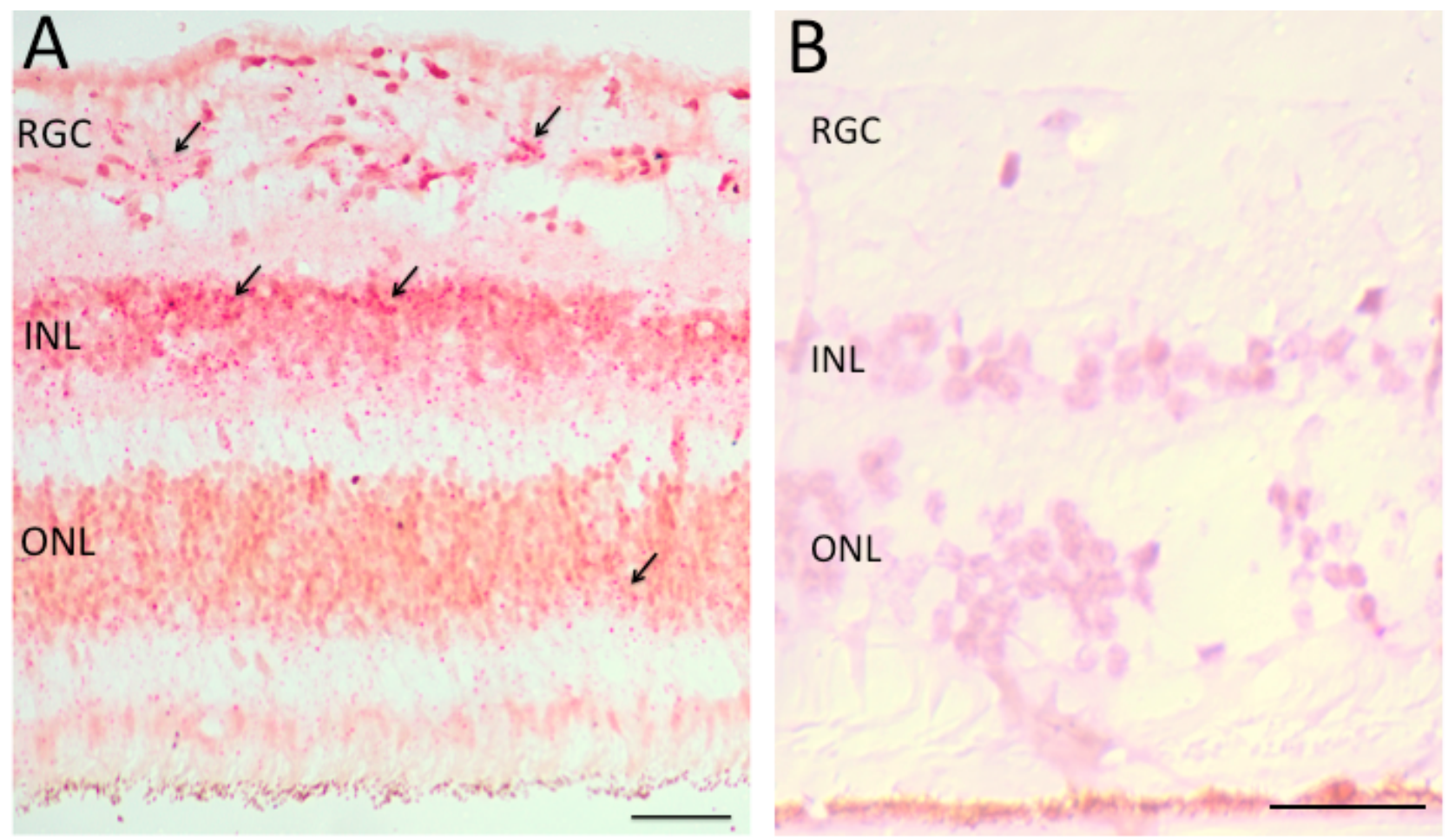

Figure 3: Her2 RNA expression in normal adjacent retina. Panel A: Her2 RNA, as detected in retinal tissue adjacent to retinoblastoma tumor by RNAScope colorimetric in situ hybridization (RNA-CISH). Red dots indicate Her2 signals. Arrows show examples of Her2 signal. Panel B: Example of retinal tissue adjacent to retinoblastoma tumor that does not exhibit Her2 signal. ONL= outer nuclear layer; $\mathrm{INL}=$ inner nuclear layer; $\mathrm{RGC}=$ retinal ganglion cell layer. Scale bar $=20$ microns.

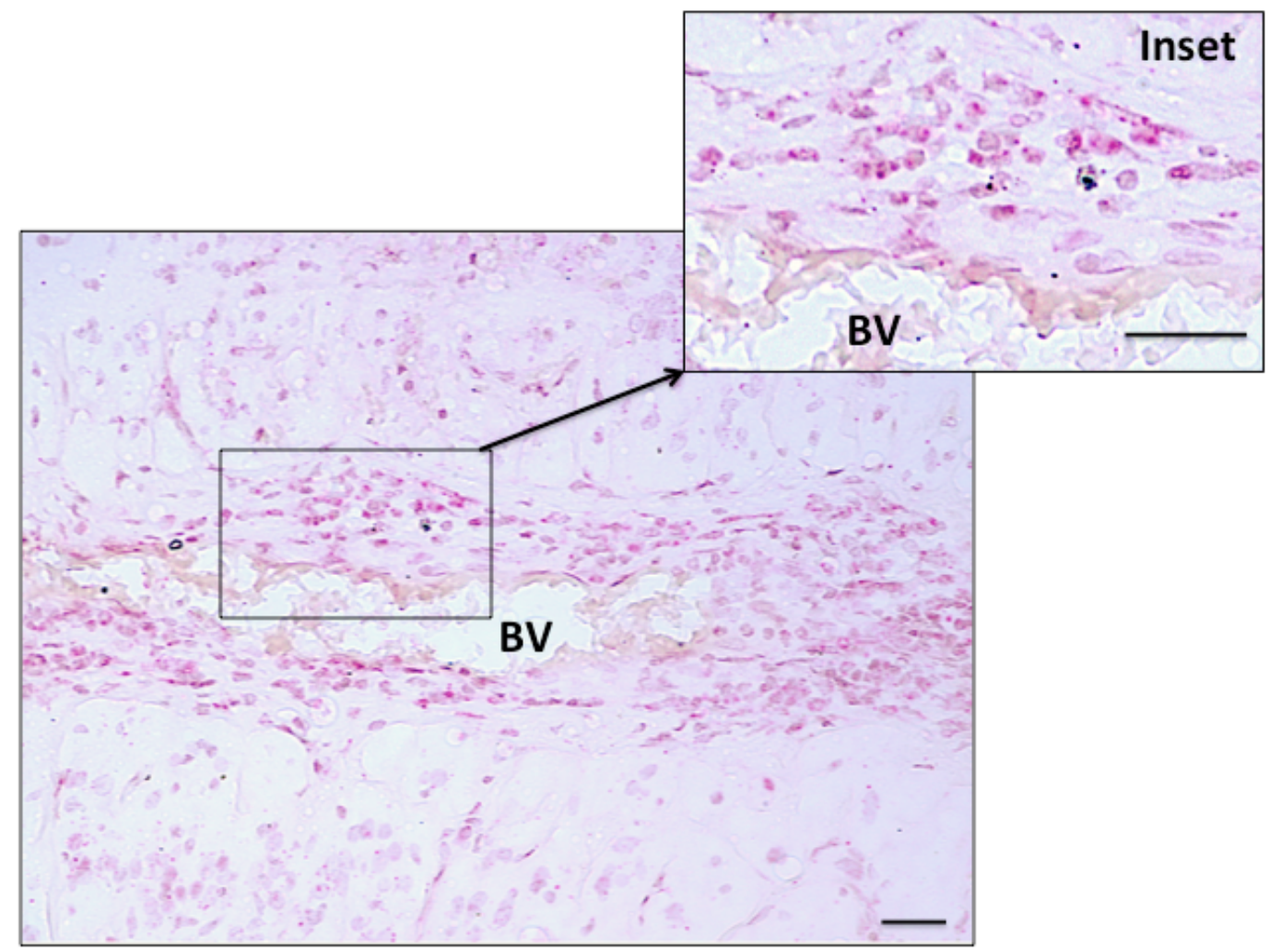

Figure 4: Her2 RNA expression in optic nerve of tumor-bearing eye. Her2 RNA adjacent to a blood vessel (BV) in the optic nerve of tumor-bearing eye detected by RNAScope colorimetric in situ hybridization (RNA-CISH). Red dots indicate Her2 signals. Inset shows higher magnification. Scale bars $=20$ microns. 
of which is shown in Figure 3. These Her2 signals were predominantly localized to the inner nuclear layer (INL) and outer nuclear layer (ONL) of the histologically normal adjacent retina, although we did see some signal in the ganglion cell layer as well. We also saw an example of increased Her 2 signal in optic nerve adjacent to a blood vessel (BV), as shown in Figure 4.

\section{Immunoreactivity of HER2 in various regions of the tumor}

In order to correlate FISH and CISH analysis with protein expression, (particularly in the transitional zone between tumor and adjacent tissue), we examined $28 \mathrm{RB}$ tumors for HER2 immunoreactivity in various regions of the tumor, including the leading edge, central tumor, vitreous seeds and transitional zone between the tumor and adjacent tissue. Examples of these regions are illustrated in Figure 5. We analyzed these images with Image $\mathrm{J}$ to assess fluorescence intensity. Normal adjacent retinal tissue was not included in ImageJ analysis, as there were not enough cases or areas of clear-cut normal adjacent tissue to be able to determine statistical significance. In general, however, we did not see intense HER2 immunoreactivity in normal adjacent retina (example shown in Figure 5). Of the 28

RB tumors examined, 14 were brighter than 2 standard deviations above the negative control, with $\mathrm{p}$ values ranging from 0.0001 to 0.0417 (Figure 6). All regions assessed were statistically more fluorescent than negative controls, with heterogeneity between individual tumors and within each tumor section. When we compared mean fluorescence intensity between the different HER2-stained tumor regions with one another, there was no significant difference.

\section{DISCUSSION}

\section{DNA-FISH vs. RNA-CISH and protein expression}

We utilized both fluorescent and colorimetric in situ hybridization as a means to localize Her2 DNA and RNA in retinoblastoma tumors and adjacent tissues. In general, RNA in situ hybridization for Her 2 has a strong correlation with FISH-DNA analysis and immunohistochemistry [12]. Interestingly, there was not complete concordance between our DNA-FISH and RNA-CISH results. Table 1 indicates that in 17 paired cases of RB tested for both DNA-FISH and RNA-CISH, there were three cases in which Her2 DNA was expressed but not Her2 RNA. This is not
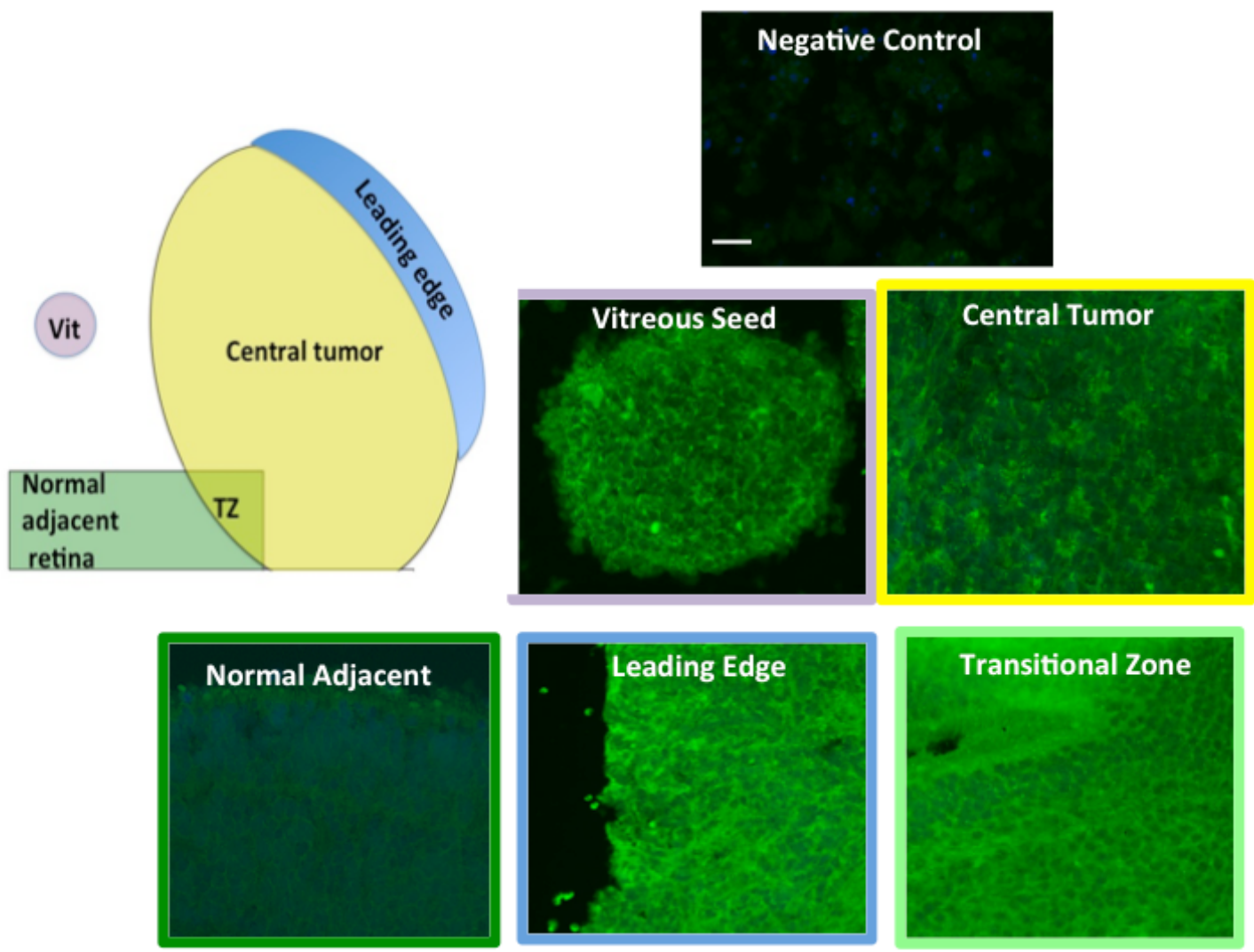

Figure 5: HER2 IHC staining. RB tumors were immunostained for HER2 as described in Methods. Diagram indicates regions that were examined. Examples of HER2 immunostaining are shown: Negative control, Central tumor, Vitreous Seed (Vit), Leading Edge, Transitional Zone (TZ), Adjacent Normal. Scale bar $=10$ microns. 
entirely unexpected, since RNA is a downstream nucleic acid product that is subject to transcriptional regulation [13]. Although RNA is less stable than DNA in fixed tissue [14], the tumor array cores were prepared and cut within a few weeks of analysis. Therefore, transcriptional regulation is the most likely explanation for the three $\mathrm{RB}$ cases that expressed Her2 DNA but not RNA.

In addition to CISH and FISH, we examined $28 \mathrm{RB}$ tumors for HER2 immunoreactivity in various regions of the tumor, including in the transitional zone between tumor and adjacent retinal tissue. Half of the tumors were considered HER2 immunoreactive (at least two standard deviations of brightness above the negative control), a smaller percentage of IHC positive tumors compared with FISH or CISH. This difference is likely due to the fact that i) these IHC tumors were not matched with FISH and CISH tumors due to tissue availablity and ii) protein expression of HER2 relies upon not only DNA expression, but also RNA expression and translation of mRNA into protein. So, it is not surprising that there would be fewer tumors immunoreactive for HER2 than Her2 positive for FISH or CISH. However, the immunoreactivity of $14 / 28$ RB tumors using the Sigma, HPA001383 antibody, in conjunction with our CISH and FISH data, reinforce our hypothesis that Her 2 is expressed in many retinoblastoma tumors at the DNA, RNA and protein levels.

\section{Her2 expression in normal adjacent tissue}

Histologically normal tissues adjacent to a tumor are often designated as "healthy control tissues" for comparative cancer studies, with the assumption that a histologically normal morphology translates to normal cell behavior. However, normal-appearing tissues adjacent to tumors may express abnormal transcriptomes [15], or exhibit other atypical characteristics, such as activated inflammatory and immune responses [16]. In human breast cancer, altered Her2 expression has been detected in $5 \%$ of peritumoral tissues [17].

In our study of RB adjacent retinal tissue, Her 2 expression is evident prior to histological transformation, particularly in the inner and outer nuclear layers of the retina. This result is especially intriguing, since live imaging of RB tumors in patients shows that early lesions are visible in the inner nuclear layer of the retina [18] and suggests that the elusive RB "cell of origin" may arise from the middle layers of the retina [19], in the same regions where we saw Her2 RNA expression in normalappearing tissues. We also saw increased Her2 RNA signal in cells surrounding a blood vessel in the optic

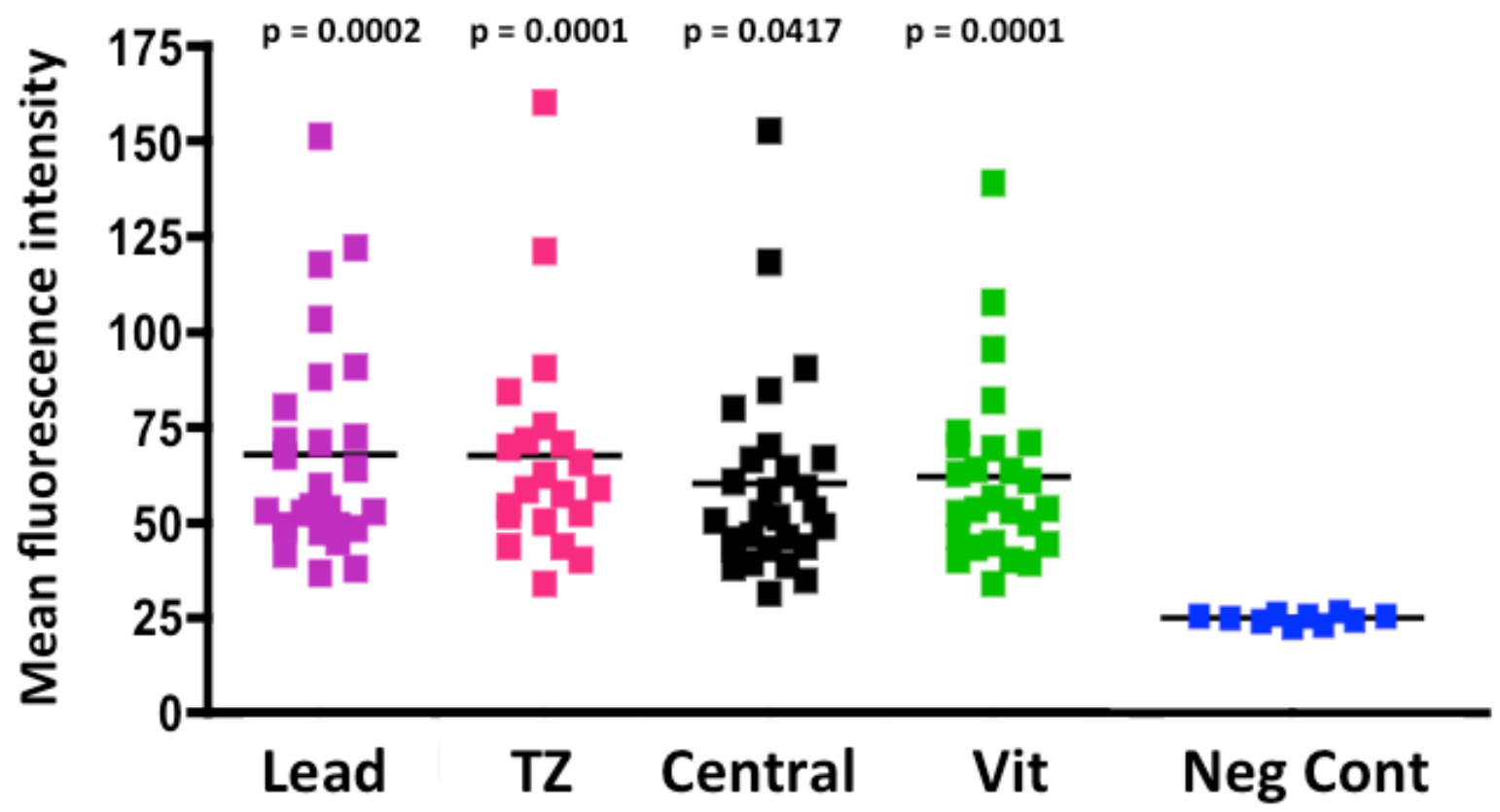

Figure 6: Immunofluorescence measurements of RB tumor regions. RB tumors were immunostained for HER2 and fluorescence intensity analyzed by Image $J$ as described in Methods. Fluorescence intensity for each region ( $Y$ axis) was compared with negative controls (Lead $=$ leading edge, $\mathrm{TZ}=$ transition zone, Central $=$ central tumor, Vit $=$ vitreous seed, Neg Cont $=$ negative control. $\mathrm{P}$ values when comparing each region with the negative control ranged from 0.0001 to 0.0417 as shown in the graph. Horizontal solid black line indicates mean fluorescence for each group. 
nerve of a tumor-bearing eye, which may be evidence of ongoing metastasis [20]. Importantly, our earlier study of normal human retina (without retinoblastoma) showed no Her2 expression, either by immunohistochemistry or by qRT-PCR [7]. Therefore, the expression of Her 2 in tumor-adjacent, morphologically normal retinal tissue and optic nerve of tumor-bearing eyes provides a new clue in the study of RB tumor progression and malignant transformation.

\section{Her 2 expression and cancer stem cells}

Many tumors contain a small percentage of cancer stem cells, with the ability to self-renew, metastasize, and confer chemoresistance (for review see [21]). Previous work from our group, confirmed by others, has demonstrated the presence of these cancer stem cell markers in human retinoblastoma [22,23,24,25]. We know that in breast cancer, Her 2 expression and overexpression is associated with a cancer stem cell phenotype (for Review, see [26]). Her2 overexpression is associated with an increased subpopulation of cancer stem cells and correlates with activation of the PI3K/AKT pathway, leading to increased expression of stem cell markers Oct3/4, Notch1, Notch2, Jagged1 and Gli1 [27]. In retinoblastoma, we do not have as much information on the role of Her 2 in the modulation of cancer stem cell behavior. However, we do know that the expression of Her 2, a truncated protein in retinoblastoma [7], remains intact at the trastuzumab binding site, with potential as a target for anti-HER2 therapy [28]. The expression of Her 2 in adjacent retina and optic nerve may be relevant to the progression of retinoblastoma, and the effect of the tumor microenvironment on surrounding retinal tissues. In turn, our findings on Her 2 expression in RB and adjacent tissues may aid in our development of strategies to target Her2 as a viable drug target or prognostic indicator in retinoblastoma.

\section{METHODS}

\section{Tissue Samples}

All human tissues in this study came from deidentified pathology cases and were considered exempt as defined by the Common Rule 45 CFR 46.102. For all experiments, paraffin-embedded human retinoblastoma samples were assessed from two sources: a repository at the Emory University Ocular Pathology Lab, and a retinoblastoma tissue array $\mathrm{BC} 35111 \mathrm{a}$ (US Biomax, Derwood, MD). Control slides included a Her+ xenograft, and a Her2 negative phaeochromocytoma tumor that was part of the tissue array.

\section{Her2 FISH}

The Her 2 FISH method was used to detect Her2 DNA in retinoblastoma tissues, "normal" adjacent retina, along with control tissues. Paraffin slides were baked at $60^{\circ} \mathrm{C}$ overnight and treated with Citrisolv (Fisher Scientific, Pittsburgh, PA) three times for $10 \mathrm{~min}$ at room temperature, followed by $100 \%$ ethanol, twice for $10 \mathrm{~min}$ at room temperature and allowed to air dry. The slides were incubated in pretreatment buffer (Vysis Paraffin Pretreatment Solution, 30-80600 which is from Vysis Paraffin Pretreatment Reagent Kit, 32-801200, Abbott Des Plaines, IL) at $80^{\circ} \mathrm{C}$ for $30 \mathrm{~min}$. The slides were rinsed in washing buffer $(2 \mathrm{x} \mathrm{SSC})$ at room temperature for 5 min, and then transferred to $\mathrm{ddH} 2 \mathrm{O}$ at room temperature for $5 \mathrm{~min}$. The slides were then treated with protease (Vysis protease, $30-806001$ ) at $37^{\circ} \mathrm{C}$ for $15 \mathrm{~min}$, rinsed in washing buffer (2x SSC) at room temperature for $5 \mathrm{~min}$, followed by ddH2O, at room temperature for $5 \mathrm{~min}$. The slides were taken through a series of alcohols $(70 \%, 90 \%$ and $100 \% \mathrm{EtOH}$ ) for $3 \mathrm{~min}$ each and allowed to air dry. Co-denaturation of the slide and probe was performed at $76^{\circ} \mathrm{C}$ for $5 \mathrm{~min}$. The Her 2 BAC clone probe (RP111065L22, RP11-449M14, made in-house) (Roohi, et al., 2008) was hybridized at $37^{\circ} \mathrm{C}$ overnight, then rinsed in 4x SSC/0.1\% Tween 20. This was followed by a series of washes: $2 \mathrm{xSSC} / 0.3 \%$ Nonidet-P40 at $72^{\circ} \mathrm{C}$ for $2 \mathrm{~min}$, $4 \mathrm{xSSC} / 0.1 \%$ Tween-20 at room temperature for $3 \mathrm{~min}$, and a final series of alcohols $(70 \%, 90 \%$ and $100 \%$ EtOH), 3 min each. The slides were allowed to air dry and coverslipped with DAPI/antifade mounting medium (Applied Spectral Imaging, Carlsbad, CAFPRPR0006).

\section{HER2 CISH}

For colorimetric in situ hybridization of RNA (RNA-CISH), we used a highly specific RNAScope Fast Red kit (Advanced Cell Diagnostics, Newark, CA) and Her2/Erbb2 human probe (\#310081, RNAscope Probe Hs-ERBB2; Advanced Cell Diagnostics) to detect RNA. For a positive control human probe, we used ubiquitin (\#310041, RNAscope ${ }^{\circledR}$ Positive Control Probe - Hs-UBC, Advanced Cell Diagnostics). The RNA in situ method was carried out according to the RNAScope kit instructions, with a two hour probe hybridization at $40^{\circ} \mathrm{C}$.

\section{HER2 immunoreactivity}

For immunohistochemistry, we examined 28 paraffin-embedded RB tumors using a rabbit anti-HER2 antibody (Sigma, HPA001383) according to our standard protocol [11]. Due to availability of tissue sections, these immunohistochemistry samples were not paired with the CISH and FISH samples. Briefly, we baked paraffin slides 
for 60 minutes at $60^{\circ} \mathrm{C}$, incubated the sections with a series of xylene and alcohols, boiled in antigen retrieval solution (sodium citrate, $\mathrm{pH}$ 6.0), and blocked for fifteen minutes at room temperature in $1 \%$ bovine serum albumin, $0.5 \%$ Triton-X100 in PBS. Slides were incubated in antiHer2 primary antibody (Sigma HPA001383) at 5ug/ $\mathrm{ml}$ (or isotype control antibody) for one hour at room temperature. Slides were washed three times in PBS and then incubated in FITC conjugated anti-rabbit secondary antibody (Sigma, stock concentration listed as ranging from $3-6.5 \mathrm{mg} / \mathrm{mL}$ ), diluted 1:400 in PBS. Slides were cover-slipped and photographed with a Nikon E600 microscope (Melville, NY) equipped with a Spot digital camera and Spot Advanced software (Sterling Heights, MI). We measured fluorescence staining intensity using Image $\mathrm{J}$ software, with three image samplings per section in the regions being measured. Some tumor sections did not have discernable regions for every parameter being measured, which accounts for the varying number of spots on each graph. Fluorescence intensities were averaged for each measurable region of the tumor, compared with fluorescence intensities of negative control images in that region, analyzed by one way ANOVA and graphed using Prism (Graphpad, San Diego, CA) software.

\section{ACKNOWLEDGEMENTS}

This work was supported by the Childhood Eye Cancer Trust (GMS, DKS) and will be presented in poster form at the Association for Research in Vision and Ophthalmology conference in Vancouver, CA in May 2019.

This paper is dedicated to the memory of Kenyan Child Life Specialist Jayne Kamau, and family support coordinator Bella Jaboma, who died aboard Ethiopian Airlines flight ET302 on March 10th, 2019 returning from the International Society of Paediatric Oncology Africa Congress in Cairo.

\section{CONFLICTS OF INTEREST}

The authors declare no potential conflicts of interest.

\section{REFERENCES}

1. Hynes NE, Stern DF. The biology of erbB-2/neu/HER-2 and its role in cancer. Biochim Biophys Acta. 1994; 1198:16584. https://doi.org/10.1016/0304-419X(94)90012-4. [PMID:7819273]

2. Gravalos C, Jimeno A. HER2 in gastric cancer: a new prognostic factor and a novel therapeutic target. Ann Oncol. 2008; 19:1523-29. https://doi.org/10.1093/annonc/mdn169. [PMID:18441328]

3. Ieni A, Barresi V, Rigoli L, Caruso RA, Tuccari G. HER2 status in premalignant, early, and advanced neoplastic lesions of the stomach. Dis Markers. 2015; 2015:234851. https://doi.org/10.1155/2015/234851. [PMID:26494937]

4. Arnaout AH, Dawson PM, Soomro S, Taylor P, Theodorou NA, Feldmann M, Fendly BM, Shepard HM, Shousha S. HER2 (c-erbB-2) oncoprotein expression in colorectal adenocarcinoma: an immunohistological study using three different antibodies. J Clin Pathol. 1992; 45:726-27. https:// doi.org/10.1136/jep.45.8.726. [PMID:1357006]

5. English DP, Roque DM, Santin AD. HER2 expression beyond breast cancer: therapeutic implications for gynecologic malignancies. Mol Diagn Ther. 2013; 17:85-99. https://doi.org/10.1007/s40291-013-0024-9. [PMID:23529353]

6. Slamon DJ, Clark GM, Wong SG, Levin WJ, Ullrich A, McGuire WL. Human breast cancer: correlation of relapse and survival with amplification of the HER-2/neu oncogene. Science. 1987; 235:177-82. https://doi.org/10.1126/ science.3798106. [PMID:3798106]

7. Seigel GM, Sharma S, Hackam AS, Shah DK. HER2/ ERBB2 immunoreactivity in human retinoblastoma. Tumour Biol. 2016; 37:6135-42. https://doi.org/10.1007/ s13277-015-4475-y. [PMID:26614428]

8. Bösch D, Pache M, Simon R, Schraml P, Glatz K, Mirlacher M, Flammer J, Sauter G, Meyer P. Expression and amplification of therapeutic target genes in retinoblastoma. Graefes Arch Clin Exp Ophthalmol. 2005; 243:156-62. https://doi.org/10.1007/s00417-004-1036-2. [PMID:15549365]

9. Sousa DC, Zoroquiain P, Orellana ME, Dias AB, Esposito E, Burnier MN Jr. HER2 Overexpression in retinoblastoma: A potential therapeutic target? Ocul Oncol Pathol. 2017; 3:210-15. https://doi.org/10.1159/000455871. [PMID:29230390]

10. Roohi J, Cammer M, Montagna C, Hatchwell E. An improved method for generating BAC DNA suitable for FISH. Cytogenet Genome Res. 2008; 121:7-9. https://doi. org/10.1159/000124374. [PMID:18544919]

11. Cassidy L, Choi M, Meyer J, Chang R, Seigel GM. Immunoreactivity of pluripotent markers SSEA-5 and L1CAM in human tumors, teratomas, and induced pluripotent stem cells. J Biomark. 2013; 2013:960862. https://doi.org/10.1155/2013/960862. [PMID:26317026]

12. Alba J, Gutierrez J, Coupe VM, Fernández B, VázquezBoquete Á, Alba J, Forteza J, García-Caballero T. HER2 status determination using RNA-ISH — a rapid and simple technique showing high correlation with FISH and IHC in 141 cases of breast cancer. Histol Histopathol. 2012; 27:1021-27. $\quad \underline{\text { https://doi.org/10.14670/HH-27.1021. }}$. [PMID:22763874]

13. Liu Q, Kulak MV, Borcherding N, Maina PK, Zhang W, Weigel RJ, Qi HH. A novel HER2 gene body enhancer contributes to HER2 expression. Oncogene. 2018; 37:687-94. $\quad$ https://doi.org/10.1038/onc.2017.382. 
[PMID:29035388]

14. Cronin M, Pho M, Dutta D, Stephans JC, Shak S, Kiefer MC, Esteban JM, Baker JB. Measurement of gene expression in archival paraffin-embedded tissues: development and performance of a 92-gene reverse transcriptase-polymerase chain reaction assay. Am J Pathol. 2004; 164:35-42. https://doi.org/10.1016/S00029440(10)63093-3. [PMID:14695316]

15. Aran D, Camarda R, Odegaard J, Paik H, Oskotsky B, Krings G, Goga A, Sirota M, Butte AJ. Comprehensive analysis of normal adjacent to tumor transcriptomes. Nat Commun. 2017; 8:1077. https://doi.org/10.1038/s41467017-01027-z. [PMID:29057876]

16. Casbas-Hernandez P, Sun X, Roman-Perez E, D'Arcy M, Sandhu R, Hishida A, McNaughton KK, Yang XR, Makowski L, Sherman ME, Figueroa ID, and Troester MA. Tumor intrinsic subtype is reflected in cancer-adjacent tissue. Cancer Epidemiol Biomarkers Prev 2015; (24) (2) 406-414. https://doi.org/10.1158/1055-9965.EPI-14-0934. [PMID:25465802]

17. Mottolese M, Nádasi EA, Botti C, Cianciulli AM, Merola R, Buglioni S, Benevolo M, Giannarelli D, Marandino F, Donnorso RP, Venturo I, Natali PG. Phenotypic changes of p53, HER2, and FAS system in multiple normal tissues surrounding breast cancer. J Cell Physiol. 2005; 204:10612. https://doi.org/10.1002/jcp.20275. [PMID:15622519]

18. Rootman DB, Gonzalez E, Mallipatna A, Vandenhoven C, Hampton L, Dimaras H, Chan HS, Gallie BL, Heon E. Hand-held high-resolution spectral domain optical coherence tomography in retinoblastoma: clinical and morphologic considerations. Br J Ophthalmol. 2013; 97:5965. https://doi.org/10.1136/bjophthalmol-2012-302133. [PMID:23104902]

19. Bremner R, Sage J. Cancer: the origin of human retinoblastoma. Nature. 2014; 514:312-13. https://doi. org/10.1038/nature13748. [PMID:25252972]

20. Kaliki S, Tahiliani P, Mishra DK, Srinivasan V, Ali MH, Reddy VA, and Kaliki S1. Tahiliani P, Mishra DK, Srinivasan V, Ali MH, Reddy VA. Optic nerve infiltration by retinoblastoma: predictive clinical features and outcome. Retina. 2016; 36:1177-83. https://doi.org/10.1097/ IAE.0000000000000861. [PMID:26583311]

21. Toledo-Guzmán ME, Bigoni-Ordóñez GD, Ibáñez Hernández M, Ortiz-Sánchez E. Cancer stem cell impact on clinical oncology. World J Stem Cells. 2018; 10:183-95. https://doi.org/10.4252/wjsc.v10.i12.183. [PMID:30613312]

22. Seigel GM, Campbell LM, Narayan M, Gonzalez-Fernandez F. Cancer stem cell characteristics in retinoblastoma. Mol Vis. 2005; 11:729-37. [PMID:16179903]

23. Seigel GM, Hackam AS, Ganguly A, Mandell LM, Gonzalez-Fernandez F. Human embryonic and neuronal stem cell markers in retinoblastoma. Mol Vis. 2007;

\section{3:823-32. [PMID:17615543]}

24. Nair RM, Balla MM, Khan I, Kalathur RK, Kondaiah P, Vemuganti GK. In vitro characterization of CD133lo cancer stem cells in Retinoblastoma Y79 cell line. BMC Cancer. 2017; 17:779. https://doi.org/10.1186/s12885-017-3750-2. [PMID:29162051]

25. Kim M, Kim JH, Kim JH, Kim DH, Yu YS. Differential expression of stem cell markers and vascular endothelial growth factor in human retinoblastoma tissue. Korean J Ophthalmol. 2010; 24:35-39. https://doi.org/10.3341/ kjo.2010.24.1.35. [PMID:20157412]

26. Nami B, Wang Z. HER2 in breast cancer stemness: A negative feedback loop towards trastuzumab resistance. Cancers (Basel). 2017; 9:40. https://doi.org/10.3390/ cancers9050040. [PMID:28445439]

27. Korkaya H, Paulson A, Iovino F, Wicha MS. HER2 regulates the mammary stem/progenitor cell population driving tumorigenesis and invasion. Oncogene. 2008; 27:6120-30. $\quad$ https://doi.org/10.1038/onc.2008.207. [PMID:18591932]

28. Kulhari H, Pooja D, Rompicharla SV, Sistla R, Adams DJ. Biomedical applications of trastuzumab: as a therapeutic agent and a targeting ligand. Med Res Rev. 2015; 35:849 76. https://doi.org/10.1002/med.21345. [PMID:25847027] 